\title{
Spatial distribution of oxygen-18 and deuterium in stream waters across the Japanese archipelago
}

\author{
M. Katsuyama ${ }^{1,2}$, T. Yoshioka ${ }^{3}$, and E. Konohira ${ }^{4}$ \\ ${ }^{1}$ Center for the Promotion of Interdisciplinary Education and Research, Kyoto Univ., Kyoto University Higashi Ichijokan, 1 \\ Yoshida Nakaadachi, Sakyo, Kyoto 606-8306, Japan \\ ${ }^{2}$ Graduate School of Agriculture, Kyoto Univ., Kitashirakawa Oiwake, Sakyo, Kyoto 606-8502, Japan \\ ${ }^{3}$ Field Science Education and Research Center, Kyoto Univ., Kitashirakawa Oiwake, Sakyo, Kyoto 606-8502, Japan \\ ${ }^{4}$ DLD Inc., Ina, 2435 Kami Yamada, Takatoh, Ina, Nagano 396-0217, Japan \\ Correspondence to: M. Katsuyama (katsuyama.masanori.5m@kyoto-u.ac.jp)
}

Received: 30 August 2014 - Published in Hydrol. Earth Syst. Sci. Discuss.: 30 September 2014

Revised: 12 March 2015 - Accepted: 13 March 2015 - Published: 31 March 2015

\begin{abstract}
The spatial distribution of oxygen and hydrogen isotopic composition $\left(\delta^{18} \mathrm{O}\right.$ and $\left.\delta^{2} \mathrm{H}\right)$ of stream waters across Japan was clarified with a data set by compiling sample data obtained from 1278 forest catchments during the summer of 2003. Both $\delta^{18} \mathrm{O}$ and $\delta^{2} \mathrm{H}$ values showed positive correlations with the mean annual air temperature and annual evapotranspiration, and negative correlations with latitude and elevation. Deuterium excess (d-excess) values in stream waters were higher on the Sea of Japan side, and lower on the Pacific Ocean side, of the Japanese archipelago. The d-excess in precipitation was generally higher in winter and lower in summer in Japan. The Sea of Japan side experiences a great deal of snowfall, and seasonal changes in monthly precipitation are rather small. In contrast, the Pacific Ocean side experiences a large amount of rainfall during summer with low levels of precipitation during the winter. Therefore, the lower d-excess in stream waters on the Pacific Ocean side reflects summer precipitation, and the higher values on the Sea of Japan side are affected by delayed recharge from snowmelt. The isoscapes of stream water connote not only spatially integrated but also temporally integrated isotope signals of precipitation and provide a framework for addressing applied hydrological, ecological, or meteorological research questions at regional scales, such as the effects of climate change.
\end{abstract}

\section{Introduction}

The importance of isoscapes, that is, the mapping of largescale spatiotemporal distributions of stable isotope compositions in various environments (West et al., 2010), is being recognized as providing a framework for fundamental and applied research questions in a wide range of fields at large scales. The Global Network for Isotopes in Precipitation (GNIP) database has been applied, for example, to monitor climate-change impacts on the character and intensity of precipitation (Aggarwal et al., 2012) and to build globally predictive GIS-based models for precipitation isoscapes (e.g., www.waterisotopes.org).

Wassenaar et al. (2009) pointed out, however, that the GNIP stations are often spatially deficient for many regions that are of interest to hydrologists as well as ecologists. For example, Wassenaar et al. (2009) mentioned that Mexico has only two GNIP stations. Moreover, Japan had also only two stations and, unfortunately, both stations in Japan were already closed. In addition, long-term monitoring of precipitation is also required. Consequently, the ground validation data for these global models are insufficient to compare at regional or country-wide scales. Under the circumstances, Wassenaar et al. (2009) hypothesized that the stable isotopic composition of surface water or groundwater, which integrates longer-term precipitation inputs (Clark and Fritz, 1997), can be a proxy for precipitation infiltration input. Indeed, some research has been undertaken regarding nationwide surface-water and groundwater isoscapes and uses them 
as an indicator of the precipitation isoscape (e.g., the British Isles: Darling et al., 2003; the United States: Kendall and Coplen, 2001; Finland: Kortelainen and Karhu, 2004; Mexico: Wassenaar et al., 2009). Although Mizota and Kusakabe (1994) have already presented the spatial distribution of stable isotope compositions of surface water in Japan, they do not discuss the mechanisms underlying the distribution. In other words, it is insufficient to test the hypothesis regarding the isotope signals of precipitation input being spatially and temporally integrated in the stream water output. Global warming will dramatically change the hydrological responses of watersheds. These changes of the hydrological responses are driven by temperature and precipitation patterns that will affect the temporal and spatial distributions of river source water over time (Marshall and Randhir, 2008). Therefore, the linkage between the precipitation and surface water at each point in time should be clarified because surface water is the most important water resource. At finer scales, the temporal variation in the stable isotope signals of precipitation and stream water have been used to estimate the mean residence time of stream water within catchments (McGuire and McDonnell, 2006; Dunn et al., 2008; Tetzlaff et al., 2011); however, few studies have been conducted in Japan (e.g., Katsuyama et al., 2010). The results of these estimates may change due to future changes in the hydrological responses of the watershed. Therefore, the establishment of a nation-wide and spatially dense stream water isotope network for Japan, which has a wide range of climatic and geographical conditions over a small area, may provide spatial isotope information fundamental for the application of isotopes in hydrological studies.

Here we present the stream water $\delta^{18} \mathrm{O}$ and $\delta^{2} \mathrm{H}$ isoscapes of the Japanese archipelago and provide multivariate regression analyses using key environmental and geographical parameters to determine which variables are the key drivers of stream water isotopic patterns. The identification of key parameters is essential in evaluating the vulnerability of hydrological responses in the watershed to climate change. Moreover, by comparing the data with existing precipitationisotope data, we consider the advantage of using stream water isoscapes as an integrated indicator of precipitation for future isotopic hydrology studies.

\section{Methods}

\subsection{Stream water sampling and measurement}

The sampling campaign Japan-Wide Stream Monitoring (JWSM) 2003 (Konohira et al., 2006) was conducted during the summer, from 1 July to 11 October of 2003, by 11 researchers. All samples were collected from forested headwater streams to avoid the influence of anthropogenic impacts such as agriculture or urban effects. We selected the potential sampling points where the whole catchment was covered by forest on the road map before the sampling, and verified the inexistence of artificial pollution source such as dams, houses and/or farmlands, and properly changed the points in the field to avoid the effects of them. There were no lakes, swaps, hot springs or other water bodies which could affect the isotope values in each catchment. The sampling points covered 45 prefectures; only two prefectures, Chiba and Okinawa, were excluded from the campaign. Samples were collected from approximately 30 catchments in each prefecture and, finally, 1278 forested headwater catchments were selected (Fig. 1). The catchment areas ranged from 0.05 to $136.8 \mathrm{~km}^{2}$ and were $5.3 \mathrm{~km}^{2}$ on average. In total, $95.3 \%$ of the catchments were smaller than $15 \mathrm{~km}^{2}$. The sampling procedures were unified between all 11 researchers prior to sampling. During the campaign, grab samples of stream water were collected once in each catchment. As the values can be affected by precipitation, we collected the samples during baseflow condition and avoided to sample during and just after the precipitation to unify the collection conditions as much as possible between sites. The collected samples were immediately filtered and preserved by freezing in polycarbonate bottles at $-10^{\circ}$ until analyzed in 2008.

The stream water samples were analyzed for both $\delta^{18} \mathrm{O}$ and $\delta^{2} \mathrm{H}$ by the Colorado Plateau Stable Isotope Laboratory using an Off-Axis Integrated Cavity Output Spectroscopy liquid water isotope analyzer (Los Gatos Model 908-0008). The measurement precision (standard deviation) was $\pm 0.2 \%$ and $\pm 0.8 \%$ for $\delta^{18} \mathrm{O}$ and $\delta^{2} \mathrm{H}$, respectively.

\subsection{Isotope data on precipitation and climate conditions}

We collected isotope data on precipitation from the published literature and unpublished data kindly offered by many researchers, in addition to our original data. The policy for collecting data was that both $\delta^{18} \mathrm{O}$ and $\delta^{2} \mathrm{H}$ were to be measured monthly or more frequently for over 1 year to calculate the mean annual weighted value of the successive precipitation inputs. The data were collected from 14 prefectures (Fig. 1 and Table 1). In three of these prefectures, Shiga (no. 6 in Fig. 1), Nara (8), and Tottori (9), the precipitation sampling has been continuous. In Shiga, the monitoring began in 1997 at the Kiryu Experimental Watershed (Kabeya et al., 2007; Katsuyama et al., 2010). Sampling began in 2004 at the Mt. Gomadan Experimental Forest in Nara (Katsuyama et al., 2008; Fukushima and Tokuchi, 2009), and in 2011 at the Hiruzen Experimental Forest of Tottori University (Haga and Katsuyama, unpublished data). The Hiruzen Forest is located on the Okayama side of the Okayama-Tottori prefectural border and the samples were collected from the mountain peak. Therefore, we term this station Tottori to clearly distinguish it from Okayama (10). At these three stations, the corresponding stream water sampling has also been continuous at the outlet of each catchment. The catchment area is 5.99 ha for Shiga, 3.15 ha for Nara, and 5.9 ha for Tottori. 


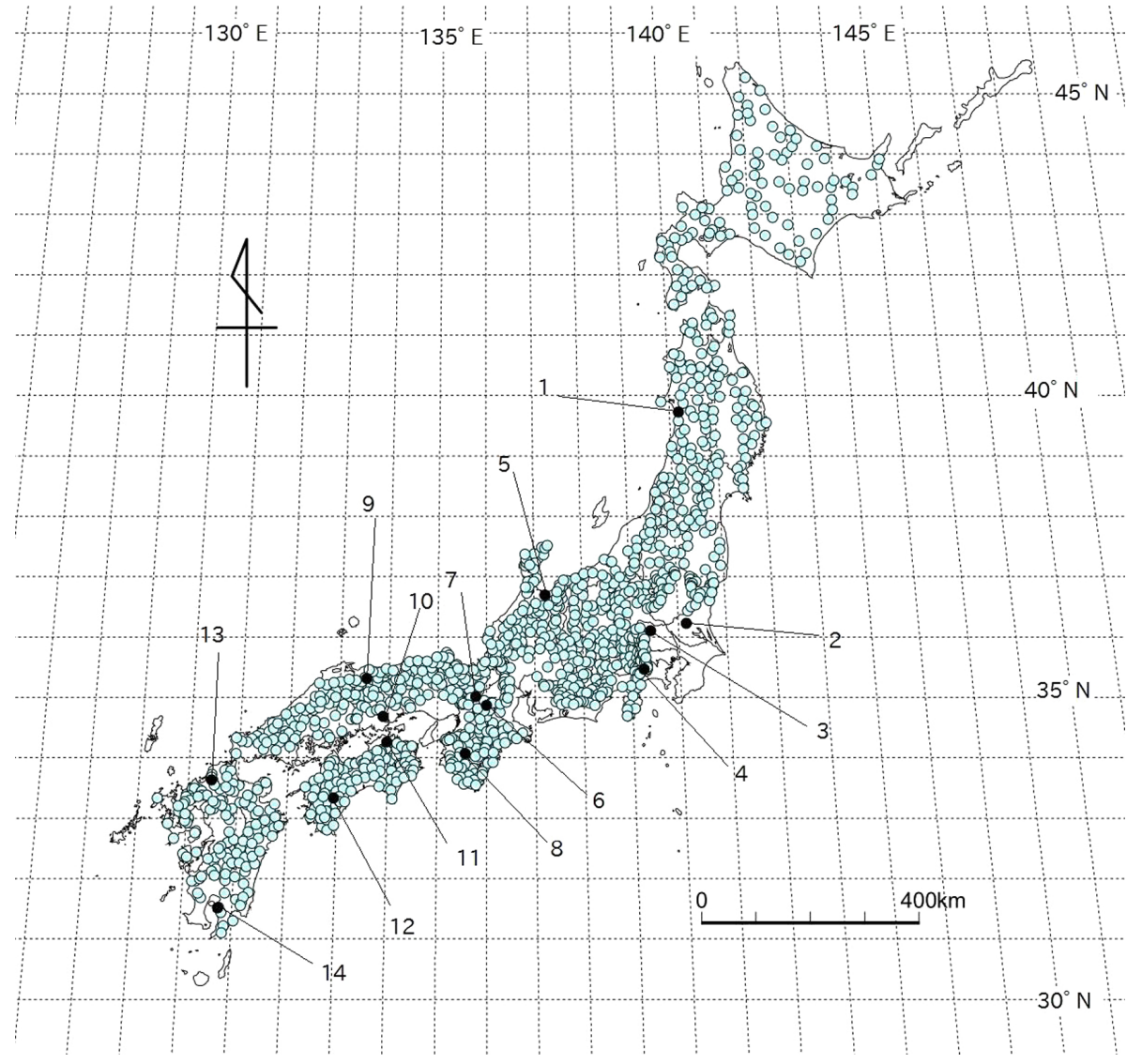

Figure 1. Index map showing locations of the 1278 stream water sampling points and the 14 sampling stations of precipitation. Light blue circles: stream water sampling points. Black circles: precipitation sampling station. The station numbers correspond to those in Table 1.

The collected samples from five of these prefectures, Shiga (6), Kyoto (7), Nara (8), Tottori (9), and Kochi (12), were sealed in small glass vials and maintained at room temperature. A mass spectrometer (Thermo Electron, MAT252) at the Center for Ecological Research, Kyoto University, with the $\mathrm{CO}_{2}-\mathrm{H}_{2} \mathrm{O}$ and $\mathrm{H}_{2}-\mathrm{H}_{2} \mathrm{O}$ equilibrium methods was used for both $\delta^{18} \mathrm{O}$ and $\delta^{2} \mathrm{H}$ analysis. The measurement precision (standard deviation) was \pm 0.05 and $\pm 0.9 \%$ for $\delta^{18} \mathrm{O}$ and $\delta^{2} \mathrm{H}$, respectively.

The isotope values of both stream water and of precipitation are reported as per mil $(\% \circ)$ units relative to the Vienna Standard Mean Ocean Water.

\subsection{Geographical and environmental parameters}

The catchment area and elevation of the site were determined using a $250 \mathrm{~m}$ digital elevation model for each sampling point. Mean annual precipitation (MAP) and mean annual temperature (MAT) were extracted from Mesh climatic data averaged for the years from 1971 to 2000 (Japan Meteorological Agency, 2002). The spatial resolution of the mesh climatic data is $1 \mathrm{~km}$. Actual evapotranspiration (AET) was extracted from Ahn and Tateishi (1994), which they esti- mated using the Priestley-Taylor method (Priestley and Taylor, 1972).

\section{Results}

\subsection{Relationship between $\delta^{18} \mathrm{O}$ and $\delta^{2} \mathrm{H}$ values in stream water}

The measured $\delta^{18} \mathrm{O}$ and $\delta^{2} \mathrm{H}$ values in stream water samples ranged from -13.7 to $-5.9 \%$ (mean $=-9.2 \%$ ) and from -92.2 to $-35.1 \%$ (mean $=-56.6 \%$ ), respectively (Table 2$)$. A clear linear relationship existed between $\delta^{18} \mathrm{O}$ and $\delta^{2} \mathrm{H}$ values (Fig. 2) as

$\delta^{2} \mathrm{H}=6.85 \delta^{18} \mathrm{O}+6.11\left(n=1278, r^{2}=0.89, p<0.001\right)$.

The data set forms a flattened ellipse around the regression line. This relationship is similar to the results from previous studies in Japan. Machida and Kondo (2003) collected isotope data for 1067 rivers and shallow groundwater sources from many papers and databases as

$\delta^{2} \mathrm{H}=6.72 \delta^{18} \mathrm{O}+3.94\left(n=1067, r^{2}=0.91\right)$. 


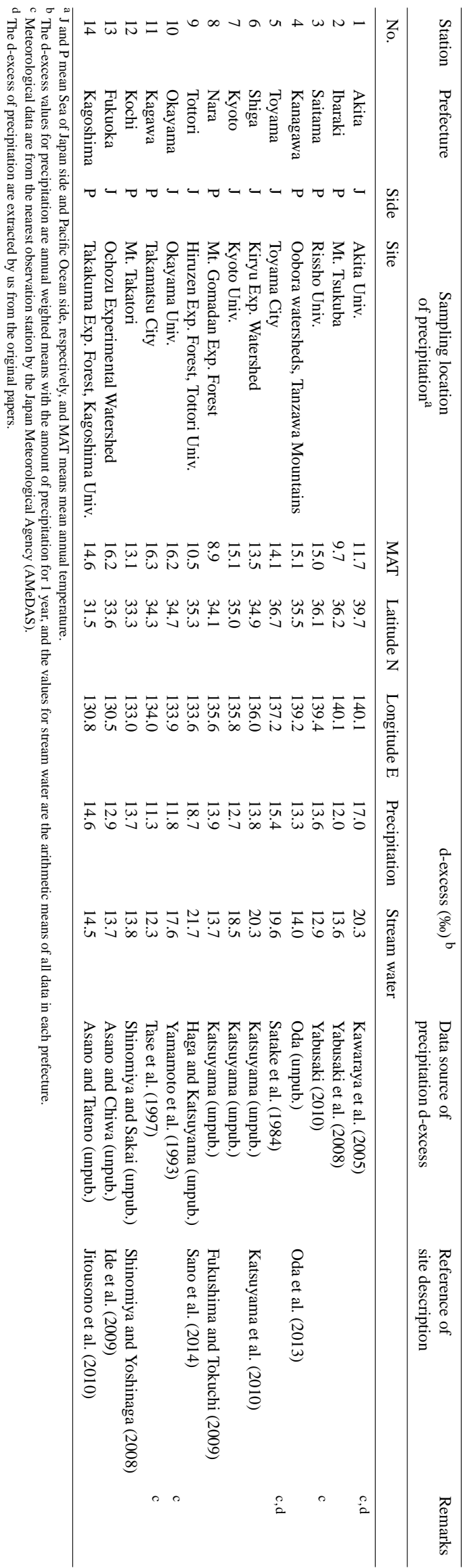

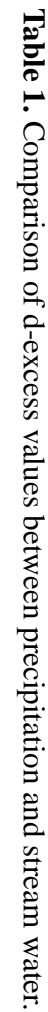

count

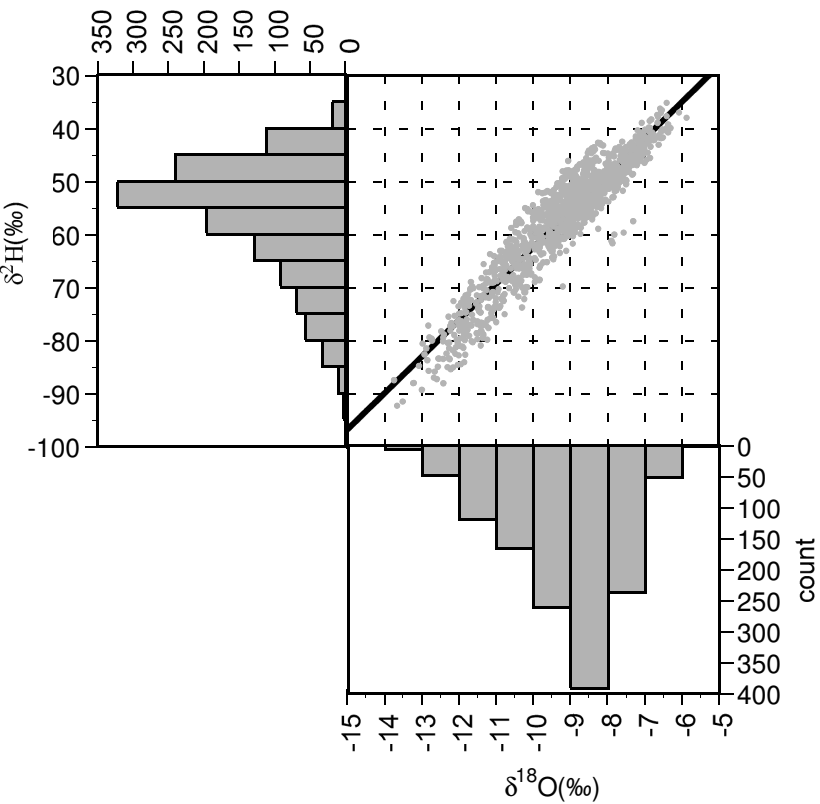

Figure 2. Relationship between $\delta^{18} \mathrm{O}$ and $\delta^{2} \mathrm{H}$ values and their frequency distributions in stream water.

Moreover, they recalculated the data for surface water and shallow groundwater presented by Mizota and Kusakabe (1994) as

$\delta^{2} \mathrm{H}=7.03 \delta^{18} \mathrm{O}+7.91 \quad\left(n=298, r^{2}=0.93\right)$.

Both the slope and the intercept of Eq. (1) are intermediate compared to those of Eqs. (2) and (3). The numbers of sampling points in this study exceeded those in Mizota and Kusakabe (1994) and Machida and Kondo (2003). However, the data presented in these previous studies were collected from samples in different years and seasons. On the other hand, the data we present here was systematically collected within a few months of the same year. Generally, surface waters show very limited isotopic seasonality compared to precipitation, due to leveling during infiltration and water movement processes within catchments. Therefore, Eq. (1) will produce a more reliable general relationship between the $\delta^{18} \mathrm{O}$ and $\delta^{2} \mathrm{H}$ of stream water in Japan.

The data are grouped into 10 regions and the linear regressions are applied to each region (Table 2). The regional division used followed that of the Japanese Meteorological Agency used for weather forecasts (see Fig. 3 for the locations of each region). The regressions for individual regions had a range of slopes and intercepts. For example, Kinki (F) - and Chugoku $(\mathrm{G})$ regions had small slopes and intercepts, although the $r^{2}$ values were low. The data from these two regions, especially from Chugoku, had a relatively narrow range of $\delta$ values and were plotted on the upper region of the data ellipse (Fig. 2). The regression lines vary strongly even within each prefecture in the Kinki and Chugoku re- 
Table 2. Range of $\delta^{18} \mathrm{O}$ and $\delta^{2} \mathrm{H}$ values in stream water samples and liner regressions for each region.

\begin{tabular}{|c|c|c|c|c|c|c|c|c|c|}
\hline & \multirow[t]{2}{*}{ Region* } & \multirow[t]{2}{*}{$n$} & \multicolumn{2}{|c|}{$\delta^{18} \mathrm{O}$} & \multicolumn{2}{|c|}{$\delta^{2} \mathrm{H}$} & \multirow[t]{2}{*}{ Slope } & \multirow[t]{2}{*}{ Intercept } & \multirow[t]{2}{*}{$r^{2}$} \\
\hline & & & $\max$. & $\min$. & $\max$ & $\min$. & & & \\
\hline A & Hokkaido & 94 & -9.0 & -13.7 & -54.7 & -92.2 & 6.94 & 6.79 & 0.87 \\
\hline B & Tohoku & 167 & -7.6 & -12.7 & -47.9 & -79.9 & 6.27 & 1.73 & 0.84 \\
\hline $\mathrm{C}$ & Kanto-Koshin & 226 & -7.1 & -13.1 & -46.1 & -89.2 & 7.07 & 4.50 & 0.93 \\
\hline $\mathrm{D}$ & Hokuriku & 124 & -7.8 & -13.2 & -43.7 & -87.9 & 7.76 & 19.38 & 0.90 \\
\hline $\mathrm{E}$ & Toukai & 105 & -6.8 & -12.4 & -38.6 & -80.1 & 6.57 & 3.20 & 0.96 \\
\hline $\mathrm{F}$ & Kinki & 175 & -6.3 & -9.9 & -37.7 & -62.0 & 5.15 & -6.96 & 0.62 \\
\hline G & Chugoku & 117 & -7.5 & -10.1 & -44.6 & -56.1 & 2.96 & -25.59 & 0.40 \\
\hline $\mathrm{H}$ & Shikoku & 111 & -6.1 & -9.8 & -35.1 & -63.2 & 8.02 & 13.91 & 0.93 \\
\hline I & Northern Kyushu & 119 & -5.9 & -9.0 & -38.0 & -56.7 & 6.27 & 0.31 & 0.87 \\
\hline $\mathrm{J}$ & Southern Kyushu & 40 & -6.4 & -8.6 & -38.3 & -56.3 & 6.80 & 4.84 & 0.73 \\
\hline & National & 1278 & -5.9 & -13.7 & -35.1 & -92.2 & 6.85 & 6.11 & 0.89 \\
\hline
\end{tabular}

* Regional division is shown in Fig. 3.

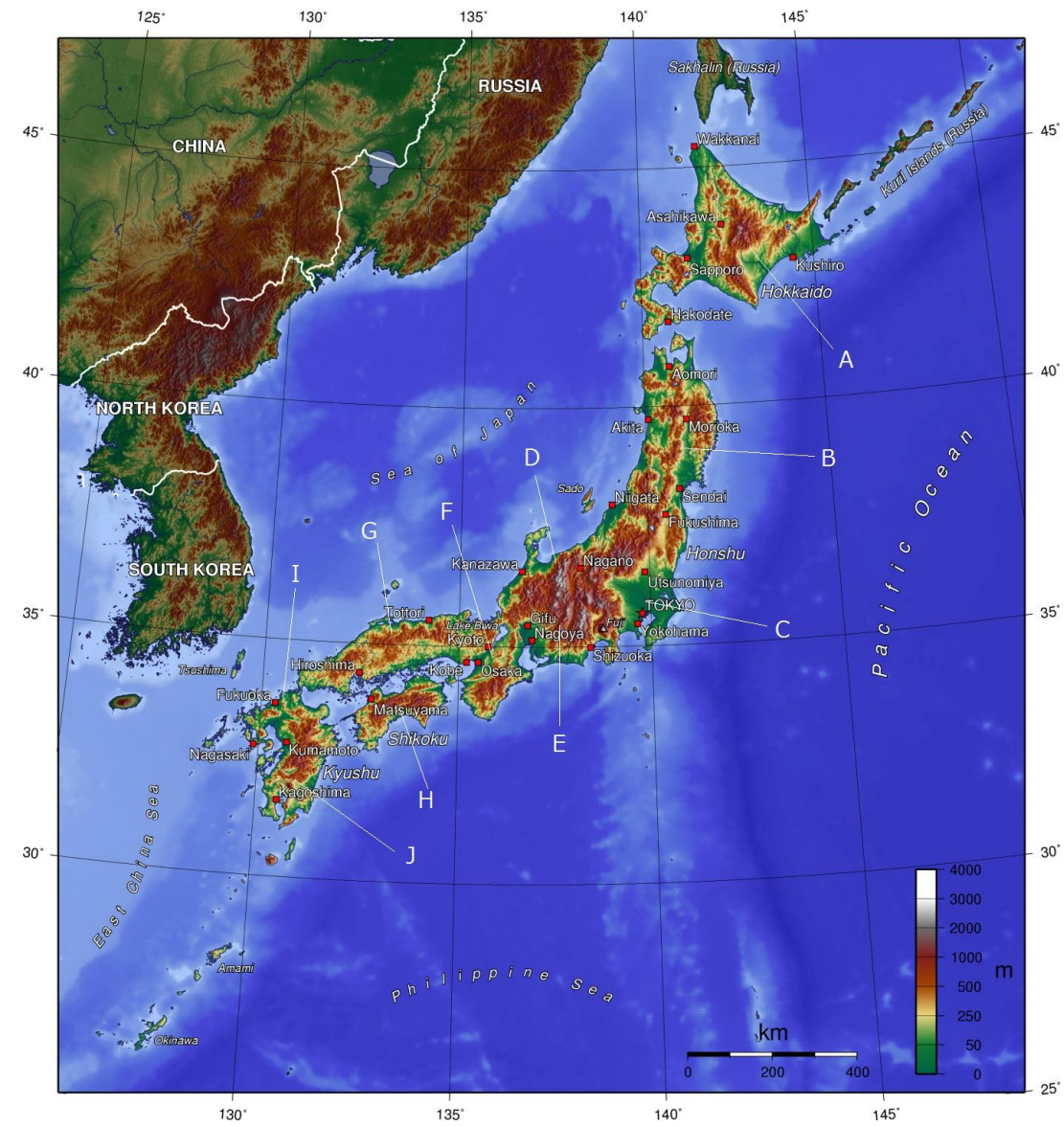

Figure 3. Topography of the Japanese archipelago and index of regional division. Note the regional division is shown in Table 2. The base map is from: http://en.wikipedia.org/wiki/File:Japan_topo_en.jpg.

gions (not shown). The slopes of these lines were relatively smaller at the prefectures of the Sea of Japan side - e.g., Shiga (1.9), Kyoto (4.5), Hyogo (3.5), Tottori (5.2), Shimane (2.3) - compared to the prefectures of the Pacific Ocean side, e.g., Nara (6.5) and Wakayama (6.8). These facts may imply that there are plural potential regression lines within the data ellipse at each region as results of the contribution from different moisture sources. To find the final solution of 
Table 3. Correlation matrix among $\delta^{18} \mathrm{O}$ and parameters LAT, ELV, ARA, MAT, MAP, and AET meaning latitude, elevation, catchment area, mean annual precipitation, mean annual temperature, and actual evapotranspiration, respectively.

\begin{tabular}{lrrrrrrr}
\hline & $\delta^{18} \mathrm{O}$ & LAT & ELV & ARA & MAT & MAP & AET \\
\hline$\delta^{18} \mathrm{O}$ & 1 & & & & & & \\
LAT & -0.65 & 1 & & & & & \\
ELV & -0.55 & -0.06 & 1 & & & & \\
ARA & -0.31 & 0.12 & 0.2 & 1 & & & \\
MAT & 0.88 & -0.73 & -0.53 & -0.35 & 1 & & \\
MAP & 0.32 & -0.43 & 0.01 & 0.1 & 0.25 & 1 & \\
AET & 0.61 & -0.88 & -0.02 & -0.12 & 0.69 & 0.44 & 1 \\
\hline
\end{tabular}

this question, however, we need more detailed observations at each prefecture scale. In other regions, the slopes were relatively similar (about 6-8); however, the intercepts were varied. These results mean that the ellipse of the data in Fig. 2 is composed of many local regression lines for the individual regions. Kendall and Coplen (2001) also found the imbricate nature of the LMWLs (local meteoric water lines) at states in the United Sates relative to the GMWL (global meteoric water line). This fact means that our data is different from the GMWL but this is not unexpected because the latter is "comprehensive" and "global".

In Japan, nationwide systematic observations of $\delta^{18} \mathrm{O}$ and $\delta^{2} \mathrm{H}$ in precipitation have not been carried out. Under such circumstances, Tase et al. (1997) presented a local meteoric water line for Japan from the observations made at 16 stations located in the Kanto region and southwest Japan as

$\delta^{2} \mathrm{H}=7.3 \delta^{18} \mathrm{O}+8.6\left(r^{2}=0.89\right)$.

Comparing the regressions for stream water (Eqs. 1-3) and for precipitation (Eq. 4), the equations appear generally similar, suggesting that the isotopic compositions of precipitation are reflected in the isotopic compositions of stream water at the national scale. The smaller slopes and interceptions in the former equations reflect the effects of evaporation during infiltration processes. However, as mentioned above, the ellipse of data in Fig. 2 is composed of many local regression lines; therefore, more precipitation data are needed to interpret the meaning of slopes at regional scales to allow these results to be discussed in detail.

\subsection{Spatial distribution of $\delta^{18} \mathrm{O}, \delta^{2} \mathrm{H}$, and d-excess values in stream water}

The Japanese archipelago is elongated from northeast to southwest, and mountains form its backbone (Fig. 3). High mountains are located at the centers of the Honshu and Hokkaido islands, named the Japan Alps (near $35-37^{\circ} \mathrm{N}$, $\left.136-139^{\circ} \mathrm{E}\right)$ and Mt. Daisetsu region ( $\left.43^{\circ} 40^{\prime} \mathrm{N}, 142^{\circ} 51^{\prime} \mathrm{E}\right)$, respectively.

The spatial distributions of $\delta^{18} \mathrm{O}$ and $\delta^{2} \mathrm{H}$ are very similar (Fig. 4a, b). Generally, the values decreased from south to north. The lower values are observed in high mountain areas at the central parts of the Honshu and Hokkaido islands. The lowest values were observed at the Mt. Daisetsu region of Hokkaido. On the other hand, the values are higher in southwestern Japan.

Deuterium excess (d-excess, $\mathrm{d}=8 \delta^{2} \mathrm{H}-\delta^{18} \mathrm{O}$; Dansgaard, 1964) is known and provides information about the climate conditions of the moisture sources. The d-excess values in stream water were clearly divided by the backbone mountain ranges of the Japanese archipelago; and the values in stream water were lower on the Pacific Ocean side and higher on the Sea of Japan side (Fig. 5). The d-excess values in stream water samples ranged from 0.9 to $26.9 \%$ o $($ mean $=16.6 \%$ o). The specifically depleted d-excess values $(\mathrm{d}<8)$ were only observed in the Gunma Prefecture located at the northern end of the Kanto Plain, while the highest values were observed in the Niigata Prefecture in the Hokuriku districts, the heaviest snowfall area in Japan. This pattern of d-excess in some parts of Japan was reported previously in the pioneer work by Waseda and Nakai (1983). They found that the d-excess of surface waters in central and northeastern Japan tended to increase continuously from the Pacific Ocean side to the Sea of Japan side, ranging from 9.1 to 22.4 .

\subsection{Seasonal variation of $d$-excess values in precipitation and stream water}

Figure $6 \mathrm{a}$ and $\mathrm{b}$ show the long-term variation of monthly $\mathrm{d}$ excess in precipitation and stream water observed at Tottori (Sea of Japan side, station no. 9 in Table 1), Shiga (Sea of Japan side, station no. 6), and Nara (Pacific Ocean side, station no. 8). The panels of Fig. 6c show typical examples of monthly d-excess values in precipitation and stream water with monthly precipitation and air temperature observed at Tottori in 2011, Shiga in 2008, and Nara in 2006. The climate conditions are clearly different among these stations. In Tottori, much snow falls from December to March with low air temperatures. In Shiga, there is less snowfall but much more rainfall during summer. Summer rainfall is more plentiful in Nara. However, similar sinusoidal d-excess variations in precipitation were repeated at these three stations every year, i.e., higher during winter and lower during summer. The sinusoidal pattern is caused by the contribution of the dual moisture sources predominantly from the Pacific Ocean in summer and predominantly from the Sea of Japan in winter (Waseda and Nakai, 1983; Araguás-Araguás et al., 1998). Moreover, Tase et al. (1997) also reported that this seasonal pattern was commonly observed at six stations in the Kanto, Shikoku, and Kyushu regions (see also Fig. 3). Unfortunately, we did not have sufficient data from 2003 when stream water sampling was conducted. Therefore, we will compare the precipitation values observed in various years with the stream water values, in the following.

Our observation was conducted from July to October. The isotope signature in stream water should have seasonal 


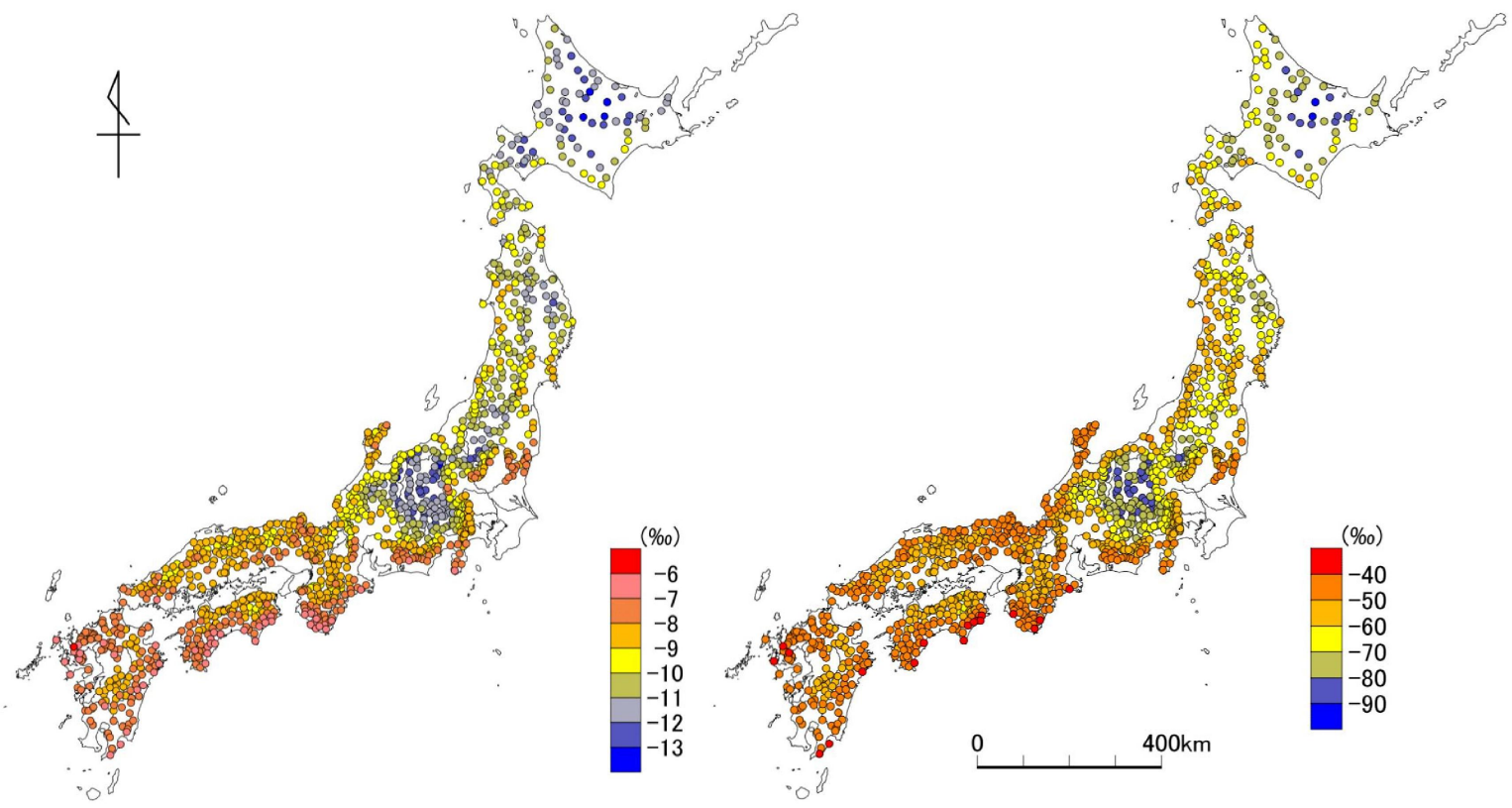

Figure 4. Spatial distribution of (a) $\delta^{18} \mathrm{O}$ (left panel) and (b) $\delta^{2} \mathrm{H}$ (right panel) values in stream water.

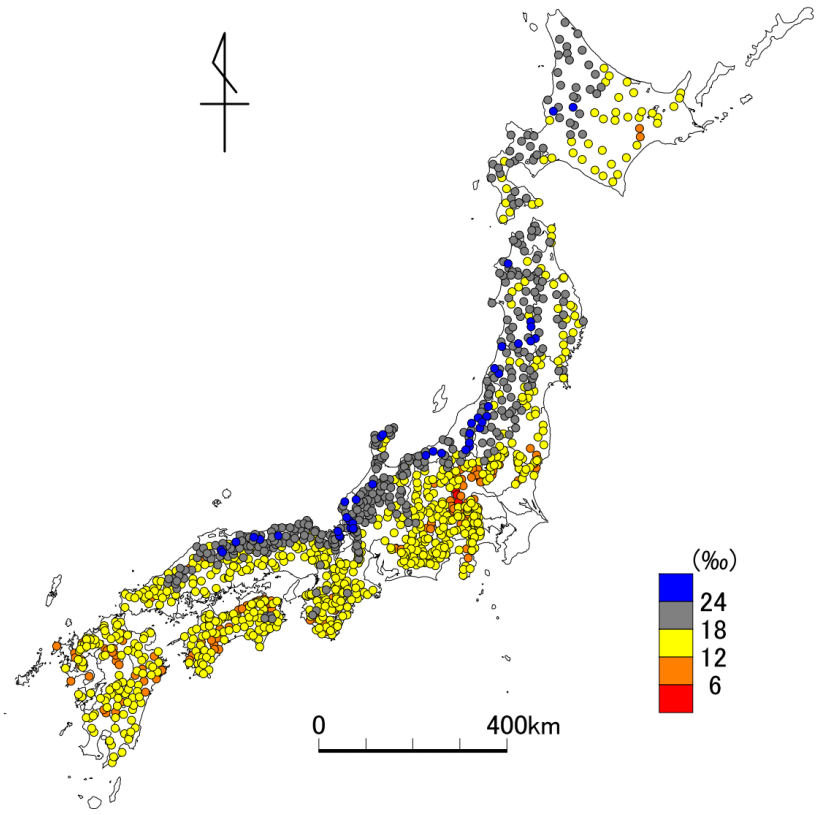

Figure 5. Spatial distribution of d-excess values in stream water.

variation and the samples may be biased depending on the date they were taken to some extent. However, as shown in Fig. 6b, the seasonality in stream water is clearly dampened compared to that in precipitation (Fig. 6a) in all stations. The coefficient of variation (CV) calculated with the 1-year data (Fig. 6c) for precipitation and stream water in each site were compared. The $\mathrm{CV}$ for precipitation and stream water were 0.50 and 0.09 in Tottori, 0.43 and 0.07 in Shiga, and 0.62

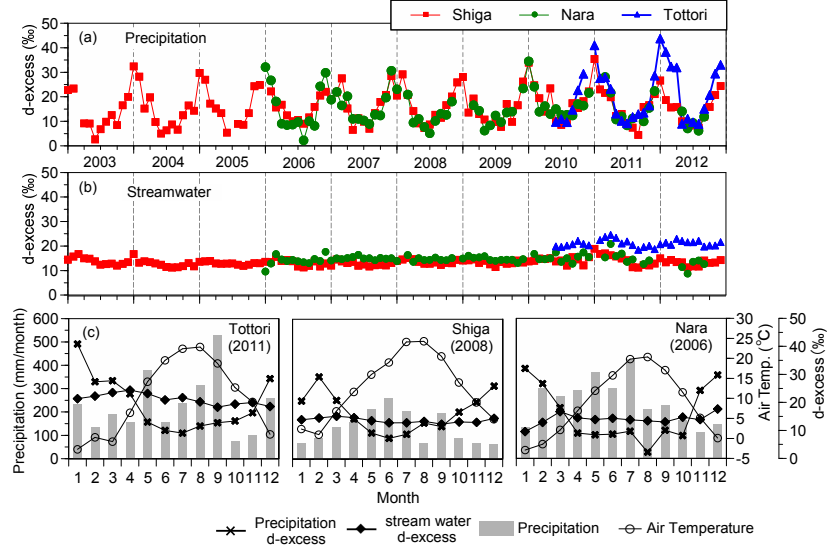

Figure 6. Seasonal variations of d-excess values in precipitation and stream water. (a) Long-term variation of monthly d-excess in precipitation. (b) Long-term variation of monthly d-excess in precipitation. (c) Typical examples of monthly d-excess values with monthly precipitation and air temperature.

and 0.14 in Nara. The CVs calculated with the data from July to October for precipitation and stream water were 0.16 and 0.07 in Tottori, 0.27 and 0.03 in Shiga, and 0.48 and 0.07 in Nara. Certainly, we cannot consider the seasonality in stream water for all of our sampling; however, these values imply that the samples are less biased depending on the date they were taken compared to the seasonality in precipitation.

The damping of the seasonality in stream water is a result of the hydrological processes within the catchment. The seasonality of d-excess values is sometimes used to estimate the water residence (and transit) times (Kabeya et al., 2007; Lee 

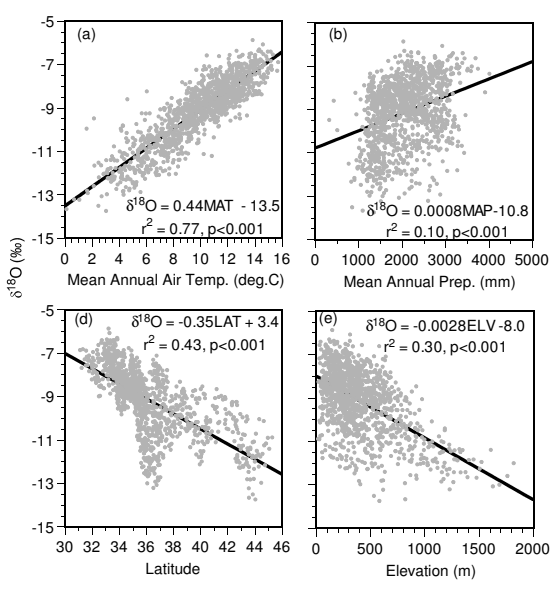

10002000300040005000 Mean Annual Prep. $(\mathrm{mm})$
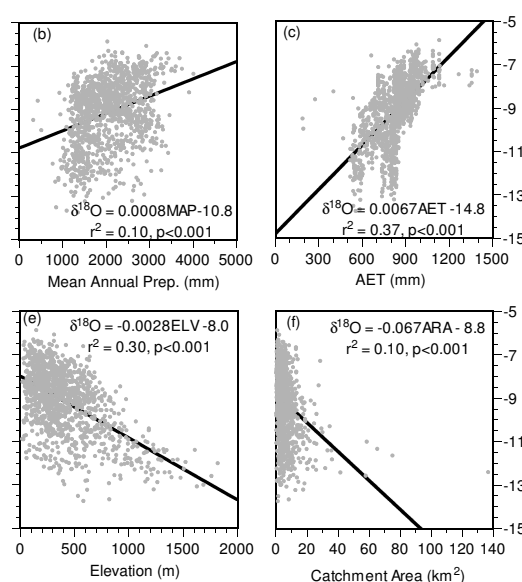

AET $(\mathrm{mm})$

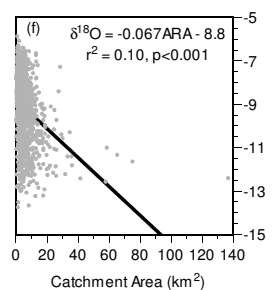

Figure 7. Correlations of $\delta^{18} \mathrm{O}$ and environmental or geographical parameters.

et al., 2007; Kim and Jung, 2014), and the smaller seasonality in stream water generally means a longer residence time. The control factors of residence times are actively argued in the scientific community; for example, the geomorphic factors (McGuire et al., 2005; Tetzlaff et al., 2009) and the bedrock permeability (Katsuyama et al., 2010) can be control factors. However, it is not necessarily controlled by simple parameters such as recharge area. In other words, the clear spatial distribution found in Figs. 4 and 5 is correct, though the residence time of our samples must be different from each other because of the complex relationship between precipitation and stream water in each catchment.

\section{Discussion}

\subsection{Correlations between $\delta^{18} \mathrm{O}$ and environmental or geographical parameters}

Generally, the $\delta^{18} \mathrm{O}$ of precipitation is affected by various environmental and geographical variables. Here, we will discuss the effect on the $\delta^{18} \mathrm{O}$ of stream water on these parameters to discuss whether the stream water can be treated as a proxy of precipitation. Stream water $\delta^{18} \mathrm{O}$ had strong positive correlations with MAT (Fig. 7a) and AET (c), as well as a negative correlation with latitude (LAT) (d) and elevation (ELV) (e), variables that are commonly used to describe the temperature, latitude, and elevation effects on precipitation isotopes. These relationships are similarly found in rivers across the United States (Kendall and Coplen, 2001), and the trends with MAT and LAT in groundwater isotopic compositions have also been observed in Finland (Kortelainen and Karhu, 2004).

Table 3 shows the correlation matrix among $\delta^{18} \mathrm{O}$ and parameters. The correlation between $\delta^{18} \mathrm{O}$ and MAT is particularly strong (Fig. 7a). The large variation in MAT reflects the geographical features of the Japanese archipelago ex- tending north and south. The AET was calculated by Priestley and Taylor's (1972) method, which increases in proportion to the net radiation. Thus, AET generally decreases at higher latitudes. Indeed, the correlation coefficient between latitude and AET was very high (Table $3, r=-0.88$ ). Therefore, the positive correlation between $\delta^{18} \mathrm{O}$ and AET (Fig. 7c) covers both the temperature effect (Fig. 7a) and the latitude effect (Fig. 7d). The scatter around latitude $35-37^{\circ} \mathrm{N}$ in Fig. 7d reflects the elevation effect around the Japan Alps area; and the relationship between $\delta^{18} \mathrm{O}$ and ELV around this area $\left(35-37^{\circ} \mathrm{N}, 136-139^{\circ} \mathrm{E}\right)$ is $\delta^{18} \mathrm{O}=-0.0027 \mathrm{ELV}$ $-8.4\left(r^{2}=0.60, p<0.01\right.$; figure not shown). The slope of the regression line for the elevation effect (Fig. 7e), i.e., the isotopic lapse rate of stream water, was $-0.28 \% \circ 100 \mathrm{~m}^{-1}$, which is the same as the global isotopic lapse rate of precipitation (Poage and Chamberlain, 2001). This result suggests that stream waters retain the properties of precipitation and, thus, the spatial patterns of stream water samples may be a suitable proxy for precipitation. However, the amount effect, which is commonly observed to be negatively correlated with precipitation, was not as clear (Fig. 7b). Moreover, no clear relationship was found between $\delta^{18} \mathrm{O}$ and catchment area (ARA) (Fig. 7f).

Based on these relationships, a multiple regression model was developed to identify the controls of environmental (MAT, MAP, and AET) and geographical (LAT, ELV, and ARA) parameters on stream water $\delta^{18} \mathrm{O}$. As noted above, however, AET was highly controlled by latitude and therefore was not appropriate as a predictor variable. The regression equation that considered the other five descriptors is as follows:

$\delta^{18} \mathrm{O}=-0.18 \mathrm{LAT}-0.0017 \mathrm{ELV}-0.015 \mathrm{ARA}+0.21 \mathrm{MAT}$

$+0.00022 \mathrm{MAP}-4.52\left(r^{2}=0.81, p<0.001\right)$.

LAT, ELV, and MAT, have higher correlations with $\delta^{18} \mathrm{O}$ than the other two parameters (Fig. 7, Table 3). Considering only these three parameters, the regression model was changed to

$\delta^{18} \mathrm{O}=-0.19 \mathrm{LAT}-0.0018 \mathrm{ELV}+0.22 \mathrm{MAT}-3.75$

$\left(r^{2}=0.80, p<0.001\right)$.

Similarly, the regression model used for stream water $\delta^{2} \mathrm{H}$ is as follows:

$$
\begin{aligned}
& \delta^{2} \mathrm{H}=-0.88 \mathrm{LAT}-0.017 \mathrm{ELV}-0.12 \mathrm{ARA}+1.36 \mathrm{MAT} \\
& +0.0041 \mathrm{MAP}-39.94\left(r^{2}=0.84, p<0.001\right) \\
& \delta^{2} \mathrm{H}=-1.39 \mathrm{LAT}-0.018 \mathrm{ELV}+1.22 \mathrm{MAT} \\
& -10.89\left(r^{2}=0.79, p<0.001\right) .
\end{aligned}
$$

These equations sufficiently explain the observed stream water $\delta^{18} \mathrm{O}$ and $\delta^{2} \mathrm{H}$. The key drivers of stream water isotopic patterns are, especially, the two geographical parameters of LAT and ELV, and one environmental parameter, 
MAT. Wassenaar et al. (2009) mentioned that the regression model approach is suitable for other countries and regions in which GNIP stations are lacking. The observed and predicted data can be linked to other investigations, such as of ecological and forensic isotope applications (Wassenaar et al., 2009; Bowen et al., 2009, 2011). Therefore, the stream water isotopic compositions in Japan predicted by these equations are applicable to other disciplines in addition to hydrological studies.

\subsection{Comparison of d-excess values in rainwater and stream water}

A comparison of isotopic composition with precipitation on a regional scale showed the connection between the source water of the stream and the meteoric input signal (Clark and Fritz, 1997; Dutton et al., 2005). Table 1 shows the comparison of d-excess values between precipitation and stream water. On the Pacific Ocean side, the d-excess values of precipitation and stream water were nearly equal: the difference was less than $1 \%$. On the Kanto Plain (stations 2, 3, and 4), the values were very close. On the Sea of Japan side, however, the values of stream water were clearly higher than those of precipitation, with a difference of more than $3 \%$, except in the Fukuoka Prefecture. These results mean that seasonal biases exist to recharge on the Sea of Japan side. Compared to the Pacific Ocean side, the Sea of Japan side experiences a great deal of snowfall, and the d-excess of meteoric input was higher in winter (Fig. 6a, c). Thus, the water recharge from late snowmelt may have affected summer stream water, even though our stream water sampling was conducted during the summer (from July to October). Fukuoka Prefecture, an exception, is located on Kyushu Island and has a warm climate with less snowfall. Thus, the d-excess of the precipitation and of the stream water was similar. Therefore, in particular on the Sea of Japan side, we must take into account the winter snowpack and spring snowmelt when considering the recharge processes of the stream. The highest d-excess of precipitation was observed in the Tottori Prefecture facing the Sea of Japan. The precipitation samples were collected at the border of the Tottori and Okayama prefectures (Haga and Katsuyama, unpublished data), and snowmelt recharges the stream water in both prefectures. Therefore, as Yamamoto et al. (1993) pointed out, the d-excess of the stream water in the Okayama Prefecture was relatively high (Table 1).

Evaporation during the infiltration processes also affect the $\mathrm{d}$-excess value. The d-excess value will be depleted when the effects of evaporation are larger. Evaporation from a forest consists of canopy interception loss and evapotranspiration from the forest floor. In our result (Fig. 5), the d-excess value is higher at the Sea of Japan side. Kondo et al. (1992) showed that the canopy interception was larger at the Sea of Japan side compared to the Pacific Ocean side because the canopy interception was positively correlated with the number of precipitation days in both coniferous and broadleaf for- est (Kondo et al., 1992; Komatsu et al., 2008), and the number was larger at the Sea of Japan side (Kondo et al., 1992). Thus, the canopy interception can make the d-excess values lower at the Sea of Japan side. On the other hand, the evaporation from forest floor estimated in Japan is generally small and negligible. For example, Tsujimura and Tanaka (1998) estimated the value as $2 \%$ of annual precipitation in central Japan. Kubota and Tsuboyama (2004) showed the values were below $10 \%$ of annual throughfall in both mature and young forests in Kanto region. These effects of evaporation may be reflected in the smaller slopes and interceptions in the regression for stream water (Eq. 1) than in the regression for precipitation (Eq. 4). However, even the effects of the evaporation, especially of the canopy interception, are considered, the difference of d-excess values at the Sea of Japan side and at the Pacific Ocean side is clear. This fact also supports that the difference is highly controlled by the recharge process in each region.

The comparison of d-excess values in precipitation with stream water demonstrates that although meteoric water has relatively spatially homogeneous isotopic compositions (Tase et al., 1997), the recharged stream water does not necessarily reflect the pattern of the meteoric water. The delayed contribution of snowmelt controlled the isotopic compositions of stream water in snowy regions. As there is no clear relationship between the catchment areas or elevation with d-excess values (figures not shown), the difference in the elevation of the actual stream water recharge area cannot be the case of differences in d-excess signatures. Moreover, the mean residence time of stream water is not controlled by catchment size (e.g., Tetzlaff et al., 2009; Katsuyama et al., 2010); therefore, the delayed contribution of snowmelt is not controlled by geographical parameters. To discuss this more directly, we need a nationwide systematic data set of isotopic compositions in precipitation. Tase et al. (1997) reported the only example of such observation. However, unfortunately, their stations were mainly located on the Pacific Ocean side, and no stations existed in the northern part of Japan, i.e., the snowy regions of Tohoku and Hokkaido. The precipitation isoscapes of the world (e.g., Bowen and Revenaugh, 2003; van der Veer et al., 2009) exactly cover the Japanese archipelago and we can compare our data with their interpolated data product. However, these studies by Bowen and Revenaugh (2003) and van der Veer et al. (2009) are based on the GNIP data. As Wassenaar et al. (2009) pointed out, the GNIP stations are often spatially deficient. There were only 2 stations in Japan, and both stations were already closed. Therefore, the GNIP data is insufficient at the small country scale such as for Japan, even if the interpolation method is perfect. Our results may fill the spatial gaps in previous studies. In other words, although comprising only one episode of sampling, our nationwide systematic data set of stream water with higher spatial density (Figs. 1, 4, 5) reveals not only spatially integrated but also temporally integrated isotope signals of precipitation, and the stream water d-excess values 
reflect the dampening of precipitation input, i.e., the differences in rainfall-runoff dynamics among the catchments.

\subsection{Vulnerability of water resources to global Warming}

As discussed above, winter snowfall recharges summer stream water at the Sea of Japan side, which experiences a great deal of snowfall. This result means that the summer water supply in this region is highly dependent on winter snowfall. Brooks et al. (2012) clarified that the water sources during summer depend on winter snow accumulated in the mountains in western Oregon and pointed out the vulnerability of the system to the influences of a warming climate, as snowpack volume is predicted to decline in the future. A decrease in snowfall caused by global warming, and the consequent vulnerability of water resources, are also predicted to occur in Japan (Kazama et al., 2008). Moreover, mean air temperature is an important environmental parameter in determining the $\delta^{18} \mathrm{O}$ and $\delta^{2} \mathrm{H}$ values of stream water, as shown in Eqs. (6) and (8). Global warming can also change vegetation cover and evapotranspiration rates in the watershed, and the resulting amount of annual runoff (Gedney et al., 2006). This implies that the importance of evapotranspiration rates as a control parameter will change over the long term. Needless to say, transit times differ among stream waters. Therefore, the isotopic signature of stream water reflects the history of precipitation in the catchment. In other words, the isoscapes of stream water represent an integrated reflection of the contribution of these environmental factors, and of the past and present climatic conditions. Therefore, this kind of research should be conducted continuously every few decades because the effects of climate change will be reflected in these isoscapes over time and can provide information regarding changes in regional hydrological and water-resource conditions.

\section{Conclusions}

The $\delta^{18} \mathrm{O}$ and $\delta^{2} \mathrm{H}$ isoscapes of stream water in Japan showed clear spatial distributions which were effectively explained by three parameters: latitude, elevation, and mean annual temperature. These parameters are commonly known as control factors of the isotopes of precipitation. Therefore, our data set is applicable, to some extent, as a proxy for the isotopic composition of precipitation in Japan. This result reflects the advantage and importance of isotope contents in stream water at a national scale, because stream water is more easily collectable than is precipitation. However, the comparison of d-excess proved that the stream water d-excess values were biased toward the values of winter precipitation in snowy regions, although our sampling campaign was conducted during the summer. These results do not merely signify the importance of continuously observing precipitation in snowy regions, but also warn us to discreetly use the tem- poral variations in isotopic signals when estimating, for example, rainfall-runoff processes and/or the mean residence time of stream water. Isoscapes of stream water reflect the recharge processes from source water and the distribution of water resources. Therefore, this technique will provide a valuable method for hydrological and ecological research, and for predicting the impacts of climate change and estimating the vulnerability of water resources at the regional scale. In particular, these results from Japan, a country with a wide range of climatic and geographical conditions across a small land area, represent a case study that will facilitate similar studies in other regions.

\section{The Supplement related to this article is available online at doi:10.5194/hess-19-1577-2015-supplement.}

Acknowledgements. We would like to thank all of the cooperators of the JWSM 2003 program for their intensive field sampling, laboratory work, and database creation. We also gratefully acknowledge the many researchers who kindly offered unpublished precipitation data. This work was conducted as part of a Research Project at the Research Institute for Humanity and Nature (Environmental Valuation Project), and partly supported by a Joint Usage/Research Grant of the Center for Ecological Research, Kyoto University and by JSPS KAKENHI grant number 25702020.

Edited by: C. Stumpp

\section{References}

Aggarwal, P. K., Alduchov, O. A., Froehlich, K. O., AraguasAraguas, L. J., Sturchio, N. C., and Kurita, N.: Stable isotopes in global precipitation: A unified interpretation based on atmospheric moisture residence time, Geophys. Res. Lett., 39, L11705, doi:10.1029/2012GL051937, 2012.

Ahn, C. and Tateishi, R.: Development of global 30-minute grid potential evapotramspiration data set, J. Jpn. Soc. Photogr. Remote Sens., 33, 12-21, 1994.

Araguás-Araguás, L., Froehlich, K., and Rozanski, K.: Stable isotope composition of precipitation over southeast Asia, J. Geophys. Res., 103, 28721-28742, 1998.

Bowen, G. J. and Revenaugh, J.: Interpolating the isotopic composition of modern meteoric precipitation, Water Resour. Res., 39, 1299, doi:10.1029/2003WR002086, 2003.

Bowen, G. J., West, J. B., Vaughn, B. H., Dawson, T. E., Ehleringer, J. R., Fogel, M. I., Hobson, K., Hoogewerff, J., Kendall, C., Lai, C.-T. Miller, C. C., Noone, D., Schwarcz, H., and Still, C. J.: Isoscapes to Address Large-Scale Earth Science Challenges, Eos Trans., 90, 109-116, 2009.

Bowen, G. J., Kennedy, C. D., Liu, Z., and Stalker, J.: Water balance model for mean annual hydrogen and oxygen isotope distributions in surface waters of the contiguous United States, J. Geophys. Res., 116, G04011, doi:10.1029/2010JG001581, 2011. 
Brooks, J. R., Wigington, Jr., P. J., Phillips, D. L., Comeleo, R., and Coulombe, R.: Willamette River Basin surface water isoscape $\left(\delta^{18} \mathrm{O}\right.$ and $\left.\delta^{2} \mathrm{H}\right)$ : temporal changes of source water within the river, Ecosphere, 3, 1-21, 2012.

Clark, I. and Fritz, P.: Environmental Isotopes in Hydrogeology, CRC Press, New York, 328 pp., 1997.

Dansgaard, W.: Stable isotopes in precipitation, Tellus, 16, 436468, 1964

Darling, W. G., Bath, A. H., and Talbot, J. C.: The O and H stable isotope composition of freshwaters in the British Isles. 2. Surface waters and groundwater, Hydrol. Earth Syst. Sci., 7, 183-195, doi:10.5194/hess-7-183-2003, 2003.

Dunn, S. M., Bacon, J. R., Soulsby, C., Tetzlaff, D., Stutter, M. I., Waldron, S., and Malcolm, I. A.: Interpretation of homogeneity in $\delta^{18} \mathrm{O}$ signatures of stream water in a nested sub-catchment system in north-east Scotland, Hydrol. Process., 22, 4767-4782, 2008.

Dutton, A., Wilkinson, B. H., Welker, J. M., Bowen, G. J., and Lohmann, K. C.: Spatial distribution and seasonal variation in ${ }^{18} \mathrm{O} /{ }^{16} \mathrm{O}$ of modern precipitation and river water across the conterminous USA, Hydrol. Process., 19, 4121-4146, 2005.

Fukushima, K. and Tokuchi, N.: Factors controlling the acidneutralizing capacity of Japanese cedar forest watersheds in stands of various ages and topographic characteristics, Hydrol. Process., 23, 259-271, doi:10.1002/hyp.7137, 2009.

Gedney, N., Cox, P. M., Betts, R. A., Boucher, O., Huntingford, C., and Stott, P. A.: Detection of a direct carbon dioxide effect in continental river runoff records, Nature, 439, 835-838, 2006.

Ide, J., Kume, T., Wakiyama, Y., Higashi, N., Chiwa, M., and Otsuki, K.: Estimation of annual suspended sediment yield from a Japanese cypress (Chamaecyparis obtusa) plantation considering antecedent rainfall, Forest Ecol. Manage., 257, 1955-1965, doi:10.1016/j.foreco.2009.02.011, 2009.

Japan Meteorological Agency, Mesh Climatic Data 2000 (CDROM), 2002.

Jitousono, T., Shimokawa, E., Teramoto, Y., Umata, H., and Inokura, Y.: Temporal variation of flow regime during 25 years in the forested catchment in the Takakuma Experimental Forest of Kagoshima University, Research bulletin of the Kagoshima University forests, 37, 115-127, (in Japanese with English summary), 2010.

Kabeya, N., Katsuyama, M., Kawasaki, M., Ohte, N., and Sugimoto, A.: Estimation of mean residence times of subsurface waters using seasonal variation in deuterium excess in a small headwater catchment in Japan, Hydrol. Process., 21, 308-322, 2007.

Katsuyama, M., Fukushima, K., and Tokuchi, N.: Comparison of rainfall-runoff characteristics in forested catchments underlain by granitic and sedimentary rock with various forest age, Hydrol. Res. Lett., 2, 14-17, 2008.

Katsuyama, M., Tani, M., and Nishimoto, S.: Connection between streamwater mean residence time and bedrock groundwater recharge/discharge dynamics in weathered granite catchments, Hydrol. Process., 24, 2287-2299, doi:10.1002/hyp.7741, 2010.

Kawaraya, H., Matsuda, H., and Matsubaya, O.: Identification of discharge components by means of oxygen and hydrogen isotopic ratios and chloride and sulfate ion concentrations in a river source region -A case study of Taihei river, Akita, Japan-, J. Jpn.
Soc. Hydrol. Water Resour., 18, 370-381, (in Japanese with English summary), 2005.

Kazama, S., Izumi, H., Sarukkalige, P. R., Nasu, T., and Sawamoto, M.: Estimating snow distribution over a large area and its application for water resources, Hydrol. Process., 22, 2315-2324, 2008.

Kendall, C. and Coplen, T. B.: Distribution of oxygen-18 and deuterium in river waters across the United States, Hydrol. Process., 15, 1363-1393, doi:10.1002/hyp.217, 2001.

Kim, S. and Jung, S.: Estimation of mean water transit time on a steep hillslope in South Korea using soil moisture measurements and deuterium excess, Hydrol. Process., 28, 1844-1857, doi:10.1002/hyp.9722, 2014.

Komatsu, H., Shinohara, Y., Kume, T., and Otsuki, K.: Relationship between annual rainfall and interception ratio for forests across Japan, Forest Ecol. Manage., 256, 1189-1197, 2008.

Kondo, J., Nakazono, M., and Watanabe, T.: Hydrological climate in Japan (2) : Forest rainfall interception, J. Jpn. Soc. Hydrol Water Resour., 5, 29-36, 1992 (in Japanese with English summary).

Konohira, E., Shindo, J., Yoshioka, T., and Toda, T.: Stream water chemistry in Japan, J. Jan. Assoc. Hydrol. Sci., 36, 146-149, (in Japanese with English Summary), 2006.

Kortelainen, N. M. and Karhu, J. A.: Regional and seasonal trends in the oxygen and hydrogen isotope ratios of Finnish groundwaters: a key for mean annual precipitation, J. Hydrol., 285, 143-157, doi:10.1016/j.jhydrol.2003.08.014, 2004.

Kubota, T. and Tsuboyama, Y.: Estimation of evaporation rate from forest floor using oxygen-18 and deuterium compositions of throughfall and stream water during a non-storm runoff periods, J. For. Res., 9, 51-59, 2004.

Lee, K., Kim, J., Lee, D., Kim, Y., and Lee, D.: Analysis of water movement through an unsaturated soil zone in Jeju Island, Korea using stable oxygen and hydrogen isotopes, J. Hydrol., 345, 199211, doi:10.1016/j.jhydrol.2007.08.006, 2007.

Machida, I. and Kondoh, A.: Stable Isotope Ratios of Natural Water in Japan - The Analysis by Using Environmental Isotopes Database, J. Jpn. Soc. Hydrol. Water Resour., 16, 556-569, (in Japanese with English Summary), 2003.

Marshall, E. and Randhir, T.: Effect of climate change on watershed system: a regional analysis, Clim. Change, 89, 263-280, 2008.

McGuire, K. J. and McDonnell, J. J.: A review and evaluation of catchment transit time modeling, J. Hydrol., 330, 543-563, 2006.

McGuire, K. J., McDonnell, J. J., Weiler, M., Kendall, C., McGlynn, B. L., Welker, J. M., and Seibert, J.: The role of topography on catchment-scale water residence time, Water Resour. Res., 41, W05002, doi:10.1029/2004WR003657, 2005.

Mizota, C. and Kusakabe, M.: Spatial distribution of $\delta \mathrm{D}-\delta^{18} \mathrm{O}$ values of surface and shallow groundwaters from Japan, south Korea and east China, Geochem. J., 28, 387-410, 1994.

Oda, T., Suzuki, M., Egusa, T., and Uchiyama, Y.: Effect of bedrock flow on catchment rainfall-runoff characteristics and the water balance in forested catchments in Tanzawa Mountains, Japan, Hydrol. Process., 27, 3864-3872, doi:10.1002/hyp.9497, 2013.

Poage, M. A. and Chamberlain, C. P.: Empirical relationships between elevation and the stable isotope composition of precipitation and surface waters: considerations for studies of paleoelevation change, Am. J. Sci., 301, 1-15, 2001. 
Priestley, C. H. B. and Taylor, R. J.: On the assessment of surface heat flux and evaporation using large-scale parameters, Mon. Weather Rev., 100, 81-92, 1972.

Sano, T., Endo, Y., Hayashi, A., and Haga, H.: Characteristics of stream water nutrient concentrations during snowmelt period in a headwater catchment in the Central Chugoku Mountains: A comparison between no-snow period and snowmelt period based on weekly sampling for one year, J. Jpn. Soc. Water Environ., 37, 119-128, (in Japanese with English summary), 2014.

Satake, H., Mukai, T., and Mizutani, Y.: Environmental isotope hydrology of precipitations and river waters in the Hokuriku district, Japan., Annual report of Tritium Research Center, Toyama University, Japan, 3, 45-56, (in Japanese with English summary), 1984.

Shinomiya, Y., and Yoshinaga, S.: Behavior of water during large scale rainfall events on the slope of natural forest in a mountainous headwater catchment in the Shimanto river basin, J. Jpn. Soc. Hydrol. Water Resour., 21, 126-139, 2008 (in Japanese with English summary).

Tase, N., Shimano, Y., Kono, T., Mori, K., Shinmi, O., Yokoyama, S., Miyazawa, T., Kodama, Y., Matsumoto, E., Fushiwaki, Y., Yasuike, S., Iijima, T., Kobayashi, M., Yamanaka, T., and Shimada, J.: Isotopic variations in precipitation of Japan, Proceedings of International Workshop on Global Change and Terrestrial Environment in Monsoon Asia, 140-143, 1997.

Tetzlaff, D., Seibert, J., McGuire, K. J., Laudon, H., Burns, D. A., Dunn, S. M., and Soulsby, C.: How does landscape structure influence catchment transit time across different geomorphic provinces?, Hydrol. Process., 23, 945-953, 2009.

Tetzlaff, D., Soulsby, C., Hrachowitz, M., and Speed, M.: Relative influence of upland and lowland headwaters on the isotope hydrology and transit times of larger catchments, J. Hydrol., 400, 438-447, 2011
Tsujimura, M. and Tanaka, T.: Evaluation of evaporation rate from forested soil surface using stable isotopic composition of soil water in a headwater basin, Hydrol. Process., 12, 2093-2103, 1998.

van der Veer, G., Voerkelius, S., Lorentz, G., Heiss, G., and Hoogewerff, J. A.: Spatial interpolation of the deuterium and oxygen-18 composition of global precipitation using temperature as ancillary variable, J. Geochem. Explor., 101, 175-184, doi:10.1016/j.gexplo.2008.06.008, 2009.

Waseda, A. and Nakai, N.: Isotopic compositions of meteoric and surface waters in Central and Northeast Japan, Chikyukagaku (Geochemistry), 17, 83-91, (in Japanese with English Summary), 1983.

Wassenaar, L. I., Van Wilgenburg, S. L., Larson, K., and Hobson, K. A.: A groundwater isoscape $\left(\delta \mathrm{D}, \delta^{18} \mathrm{O}\right)$ for Mexico, J. Geochem. Explor., 102, 123-136, doi:10.1016/j.gexplo.2009.01.001, 2009.

West, J. B., Bowen, G. J., Dawson, T. E., and Tu, K. P. (Eds.): Isoscapes. Understanding movement, pattern, and process on Earth through isotope mapping, Springer, Dordrecht, the Netherlands, 487 pp., doi:10.1007/978-90-481-3354-3, 2010.

Yabusaki, S.: Characteristics of stable isotopes in precipitation at Kumagaya city, Saitama prefecture, Bulletin of Faculty of Geo-environmental Science, Rissho University, 12, 121-125, (in Japanese), 2010.

Yabusaki, S., Tase, N., Tsujimura, M., and Hayashi, Y.: Characteristics of Stable Isotopes in Precipitation at South Slope of Mt Tsukuba, Bull. of the Terrestrial Environment Research Center, University of Tsukuba, 9, 15-23. (in Japanese with English Summary), 2008.

Yamamoto, M., Kitamura, T., Akagi, H., Furukawa, T., and Kusakabe, M.: Hydrogen and Oxygen isotope ratios of meteoric waters in Okayama prefecture, Japan, J. Groundwater Hydrol., 35, $107-$ 112, (in Japanese with English Summary), 1993. 